
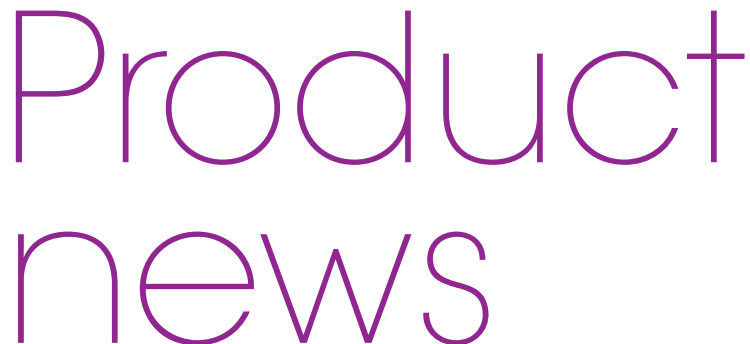

Product news is provided as a service to readers using text and images from the manufacturer, supplier or distributor and does not imply endorsement by BDJ Team. Normal and prudent research should be exercised before purchase or use of any product mentioned.

\section{GET SMART ABOUT SHARPS}

Needlestick injuries can transfer serious infections including hepatitis B, hepatitis $\mathrm{C}$ and HIV. Keep safe and get smart about sharps by using the InSafe Sharps Safety System by Initial Medical.

Completely compliant with government legislation, this unique sharps and syringes disposal box has been designed so that the needles are never

exposed apart from when administering the injection. This prevents needles from causing accidents both before and after injections, heavily reducing the chances of needlestick injuries and the spread of infections.

The syringe also aspirates and behaves

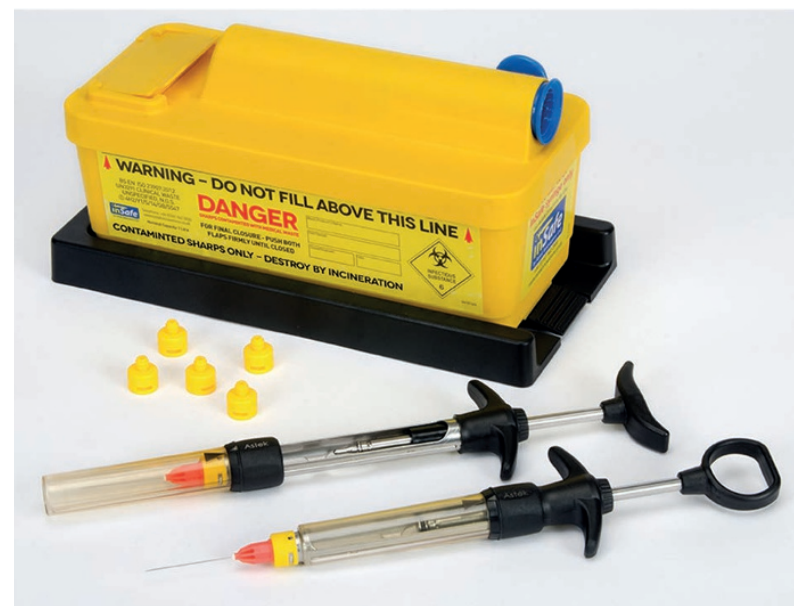

exactly like a normal syringe, meaning that there will be no interruptions to your service.

For further information, please visit www.initial.co.uk/medical or Tel: 0870 8504045.

\title{
MEET TANDEX, YOUR PARTNER IN PREVENTION
}
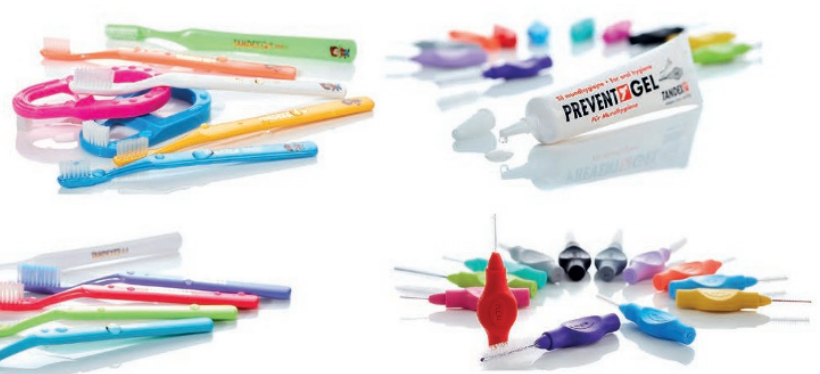

for all ages, plus PREVENT GEL and a mouthwash for optimal protection. TANDEX has everything for daily self-care. The company is proud of its environmental credentials too, with products made

Loved by dentists, hygienists and dental therapists, each Tandex product will perform the preventive work it has been designed for. TANDEX is known for the FLEXI $^{\text {sx }}$ - the new generation of interdental brushing - but it also produces brushes without harmful chemicals and allergyfree for patients' comfort. For more information on Tandex's range of products, visit www.tandex.dk or the facebook page: www.facebook.com/pages/TandexUK/234855250044190? fref $=$ ts.

\section{FOR THE TEAM!}

The ADI Team

Congress 2019 will

provide education

and networking

for all dental team

members. Julia

Wilson, ADI DCP

representative

and moderator

of the Hygienists

and Therapists

Programme,

commented:

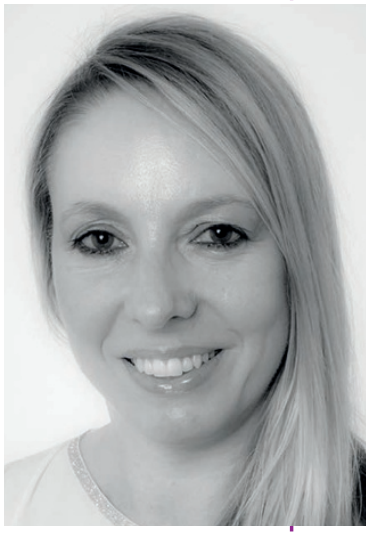

'We are delighted to present what I think is a very varied and exciting programme for team members at the ADI Team Congress 2019. We have created an outstanding lineup of speakers to discuss a dynamic range of topics that are relevant to professionals right now.

'The ADI Team Congress offers a wonderful opportunity for professionals to get together, learn from each other and enjoy a fun-packed social programme. Dentistry - and especially dental implantology - works best with a collaborative approach from all team members and this event provides education and networking for all. The ADI Team

Congress is always an awesome event and I expect 2019 to be no different.

ADI Team Congress 2019, Shaping the Future of Dental Implantology:

Techniques - Technology - Teamwork 2 4 May 2019, EICC, Edinburgh.

\section{GAIN CPD ONLINE}

Are you looking for a convenient way to gain CPD? By becoming a member of the Association of Dental Implantology (ADI) you be granted access to a growing library of online resources and can also add to your CPD by watching ADI Webinars.

Accessible at any time, anywhere, to any team member, these educational resources cover a diverse range of topics relating to dental implantology and are invaluable for those looking to incorporate high quality CPD within their professional development plan.

ADI Webinars are just one of many exciting benefits of becoming a member of the ADI - find out more by visiting the website today. For more information please visit www.adi.org.uk. 